University of Nebraska - Lincoln

DigitalCommons@University of Nebraska - Lincoln

\title{
Growth mechanisms of multiscale, mound-like surface structures on titanium by femtosecond laser processing
}

\author{
Edwin Peng \\ University of Nebraska-Lincoln, epeng2@unl.edu \\ Ryan Bell \\ University of Nebraska at Kearney, campbellbm@unk.edu \\ Craig A. Zuhlke \\ University of Nebraska-Lincoln, czuhlke@unl.edu \\ Meiyu Wang \\ University of Nebraska-Lincoln \\ Dennis R. Alexander \\ University of Nebraska-Lincoln, dalexander1@unl.edu
}

See next page for additional authors

Follow this and additional works at: https://digitalcommons.unl.edu/mechengfacpub

Part of the Mechanics of Materials Commons, Nanoscience and Nanotechnology Commons, Other Engineering Science and Materials Commons, and the Other Mechanical Engineering Commons

Peng, Edwin; Bell, Ryan; Zuhlke, Craig A.; Wang, Meiyu; Alexander, Dennis R.; Gogos, George; and Shield, Jeffrey E., "Growth mechanisms of multiscale, mound-like surface structures on titanium by femtosecond laser processing" (2017). Mechanical \& Materials Engineering Faculty Publications. 328.

https://digitalcommons.unl.edu/mechengfacpub/328

This Article is brought to you for free and open access by the Mechanical \& Materials Engineering, Department of at DigitalCommons@University of Nebraska - Lincoln. It has been accepted for inclusion in Mechanical \& Materials Engineering Faculty Publications by an authorized administrator of DigitalCommons@University of Nebraska Lincoln. 


\section{Authors}

Edwin Peng, Ryan Bell, Craig A. Zuhlke, Meiyu Wang, Dennis R. Alexander, George Gogos, and Jeffrey E. Shield 


\title{
Growth mechanisms of multiscale, mound-like surface structures on titanium by femtosecond laser processing
}

\author{
Edwin Peng, ${ }^{1, a)}$ Ryan Bell, ${ }^{2}$ Craig A. Zuhlke, ${ }^{2}$ Meiyu Wang, ${ }^{1}$ Dennis R. Alexander, ${ }^{2}$ \\ George Gogos, ${ }^{1}$ and Jeffrey E. Shield ${ }^{1}$ \\ ${ }^{1}$ Department of Mechanical and Materials Engineering, University of Nebraska-Lincoln, Lincoln, \\ Nebraska 68588, USA \\ ${ }^{2}$ Department of Electrical and Computer Engineering, University of Nebraska-Lincoln, Lincoln, \\ Nebraska 68588, USA
}

(Received 16 June 2017; accepted 20 September 2017; published online 4 October 2017)

\begin{abstract}
Femtosecond laser surface processing (FLSP) can be used to functionalize many surfaces, imparting specialized properties such as increased broadband optical absorption or superhydrophobicity/-hydrophilicity. In this study, the subsurface microstructure of a series of mound-like FLSP structures formed on commercially pure titanium using five combinations of laser fluence and cumulative pulse counts was studied. Using a dual beam Scanning Electron Microscope with a Focused Ion Beam, the subsurface microstructure for each FLSP structure type was revealed by cross-sectioning. The microstructure of the mounds formed using the lowest fluence value consists of the original Ti grains. This is evidence that preferential laser ablation is the primary formation mechanism. However, the underlying microstructure of mounds produced using higher fluence values was composed of a distinct smaller-grained $\alpha$-Ti region adjacent to the original larger Ti grains remaining deeper beneath the surface. This layer was attributed to resolidification of molten Ti from the hydrodynamic Marangoni effect driven fluid flow of molten $\mathrm{Ti}$, which is the result of the femtosecond pulse interaction with the material. Published by AIP Publishing. https://doi.org/10.1063/1.4990709
\end{abstract}

\section{INTRODUCTION}

Femtosecond laser surface processing (FLSP) is an emerging technology for the creation of functionalized surfaces through the formation of self-organized, multiscale surface structures. ${ }^{1-5}$ FLSP is applicable for a wide range of materials, including metals, ${ }^{5-9}$ semiconductors, ${ }^{10,11}$ polymers, ${ }^{12-14}$ glass, ${ }^{15,16}$ and ceramics. ${ }^{17,18}$ The resulting micro/ nanostructures provide special surface properties with many potentially useful applications. These include optimizing optical absorption for photovoltaics ${ }^{17,19,20}$ and photodiodes, ${ }^{21,22}$ as well as altering wetting properties (superhydrophilic or superhydrophobic) for enhanced heat transfer, ${ }^{23-25}$ self-cleaning surfaces, ${ }^{26}$ and chemical sensors. ${ }^{27}$

FLSP on titanium (Ti) surfaces is of great interest, especially for biomedical applications. Ti-based alloys are well established, widely used materials for implants due to their low density, high mechanical strength, and biocompatibility. $^{28,29}$ The wide range of Ti-based medical implants include dental prostheses, hearing aide, pacemakers, and joint replacements. Micro/nanostructures on laser processed Ti surfaces promote integration of biomedical implants with the cells in the recipient's body cells and reduce bacterial growth. ${ }^{30-32}$

Furthermore, there are many non-biological applications of surface laser processing of commercially pure $\mathrm{Ti}$ and $\mathrm{Ti}$ alloys. FLSP can be used to create low reflectivity, high absorption surfaces for light with wavelengths from ultraviolet to terahertz radio waves. ${ }^{33-36}$ Such optoelectronic properties

\footnotetext{
a) Author to whom correspondence should be addressed: edwin.peng@ huskers.unl.edu
}

can be used for solar thermal energy conversion, molecular spectroscopy, plasmonics, and stealth technologies. Recently, FLSP of Ti has been shown to improve wear for tribological applications. ${ }^{37,38}$ Lastly, regular grooved surface structures can serve as molds for economical, mass production of polymers with functionalized surfaces. ${ }^{39}$

When applying FLSP on a metal surface, different combinations of laser fluence and laser pulses per unit area result in many distinct types of self-organized micro/nanostructures. ${ }^{5,8,40-42}$ Zuhlke et al. described seven unique categories of micro/nanoscale structures that formed when applying FLSP onto Ni 200/201 in the fluence range of ablation threshold to $3 \mathrm{~J} \mathrm{~cm}^{-2}$ and cumulative pulse counts from 1 to 20000 pulses. A map of these fluence and pulse count combinations is presented in Fig. 1. ${ }^{5,43}$ Each unique structure type is formed by a dynamic balance of laser induced mechanisms.

At a low laser fluence, i.e., near the material's ablation threshold, FLSP forms laser-induced periodic surface structures (LIPSSs) and nanoparticle-covered pyramids (NC pyramids). ${ }^{6,41,44,45}$

LIPSS are ripples oriented either parallel or perpendicular to the laser's polarization, depending on the target material and laser parameters, and have periods with the same order of magnitude as the laser wavelength. $8,37,45-48$ They form after a low number of laser pulses $(\sim 10$ to 1000$){ }^{2}$

Additional laser pulses in the same fluence range that creates LIPSS can develop NC pyramids. ${ }^{41,44,45}$ These structures can be $50 \mu \mathrm{m}$ or greater in height, and are covered with a layer of nanoparticles typically more than $2 \mu \mathrm{m}$ thick. NC pyramids start as small $(<10 \mu \mathrm{m})$ precursor cones that increase in height relative to the valleys between the 


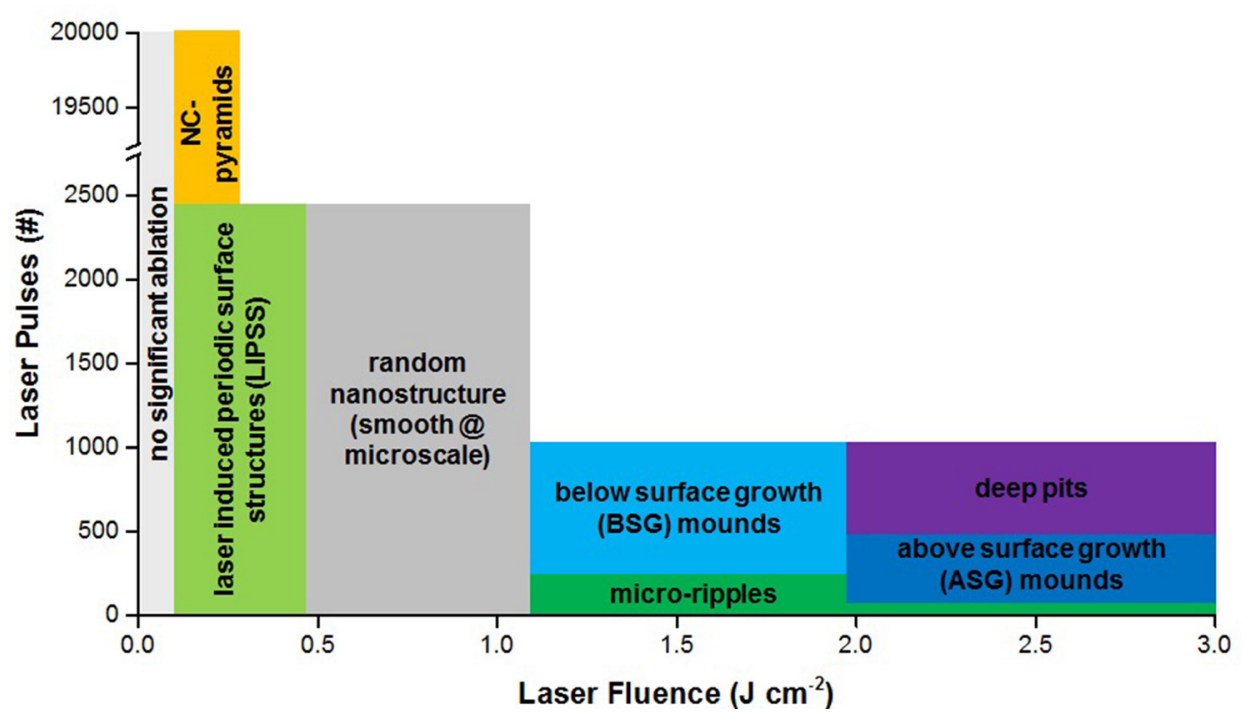

FIG. 1. FLSP surface structure types formed on $\mathrm{Ni}$ 200/201., ${ }^{5,43}$

structures via preferential laser ablation (PVA). Furthermore, $\mathrm{NC}$ pyramids increase in height by redeposition of nanoparticles produced during the laser ablation process.

FLSP of metal surfaces at fluence levels greater than those for LIPSS and NC pyramid formation can result in quasiperiodic, mound-like structures. ${ }^{5,40,49}$ These mounds range in size from several microns to over $100 \mu \mathrm{m}$ and are covered by additional nanoscale structures and/or nanoparticles. These mound-like structures are often applied to make the metal surfaces superhydrophilic ${ }^{24}$ or superhydrophobic. ${ }^{50}$

In previous studies, Zuhlke et al. categorized mounds on Ni 200/201 into two classes: below-surface-growth (BSG) and above-surface-growth (ASG) mounds. ${ }^{5,40,43}$ BSG mounds are tightly spaced, have a low height-to-width aspect ratio $(\sim 1: 1)$, and have peaks which are below the original surface of the target material. In contrast, ASG mounds are spaced further apart, separated by deep pits, have a high aspect ratio $(>2: 1)$, and protrude up to several microns above the original surface. Zuhlke et al. reported that BSG mound formation occurs in the fluence range of approximately 1 to $2 \mathrm{~J} \mathrm{~cm}^{-2}$ and ASG mounds at approximately 2 to $3 \mathrm{~J} \mathrm{~cm}^{-2}$ on Ni-based alloys. $^{5,40,43}$ These fluence values are higher by as much as two orders of magnitude than the ablation threshold of $\mathrm{Ni}$ $\left(0.05\right.$ to $\left.0.1 \mathrm{~J} \mathrm{~cm}^{-2}\right) .{ }^{51-53}$

Both BSG and ASG mounds are thought to originate from small precursor ripples, mounds, and pits that develop after a low number of laser pulses (120 pulses for BSG, $<30$ pulses for ASG). ${ }^{5}$ These precursor sites cause an inhomogeneous distribution of laser energy for subsequent pulses, leading to the formation processes thought to produce BSGand ASG mounds. ${ }^{5,40}$

One of the formation processes associated with FLSP mounds is preferential valley ablation (PVA). PVA is the process where the valleys, or lower areas of the surface, are ablated more than at the peaks of the precursor mounds. 5,45,54 Two phenomena contribute to PVA: (a) the higher fluence in the valleys than on the sides of the mounds due to larger subtended area resulting from the increased incident angle and (b) a portion of the light incident on the sides of the peaks scattered onto the valleys. BSG mounds on metals, and similar "spikes" on Si substrates, are believed to be formed primarily through PVA.

A second FLSP mound formation mechanism is fluid flow (FF), the hydrodynamic process where the irradiated surface melts, and the subsequent liquid layer flows away from the (higher fluence) valleys up the sides of the structures (lower fluence) and towards the peaks. Resolidification of this layer increases the height of the peaks, and is thought to be a significant part of the ASG mound formation process. ${ }^{5,54}$ FF is most likely due to the Marangoni effect, as previous researchers have also reported about FLSP structures. $^{47,55}$ Lastly, redeposition of the ablated material can also contribute to mound growth. ${ }^{5}$

Examining the growth mechanisms of FLSP structures' can add understanding of the physics behind laser-matter interaction and can provide the ability to tailor surface features for improved performance in specific applications. There have been several previous studies on laser processed surface structures of silicon and metals that utilize crosssectional analysis for this purpose. 7,40,54,56,57

In this paper, cross-sectional analysis is used to study the underlying microstructure of mounds on Ti formed by FLSP using different laser fluence and pulse counts. The Ti mounds have similarities to FLSP structures previously reported on $\mathrm{Ni}^{5}$ and metallic glass alloy $\mathrm{Ni}_{60} \mathrm{~N}_{40}{ }^{54,58}$ However, a transition between below surface and above surface growth has not been fully studied on $\mathrm{Ti}$, so the mounds in this paper are only identified in terms of the FLSP fluence and pulse counts. Using the cross-sectional analysis, evidence of thermal events like resolidification after fluid flow or oxidation when laser processing is undertaken in the presence of oxygen. This study is, to the authors' best knowledge, the first to provide material science-based evidence of the wide range of FLSP structures on $\mathrm{Ti}$.

\section{MATERIALS AND METHODS}

The material used in this study was the commonly utilized, commercially pure Ti Grade 2 from McMaster-Carr in the form of $1.6 \mathrm{~mm}$ thick sheets. ${ }^{59}$ The microstructure of the Ti substrate was characterized using scanning electron 


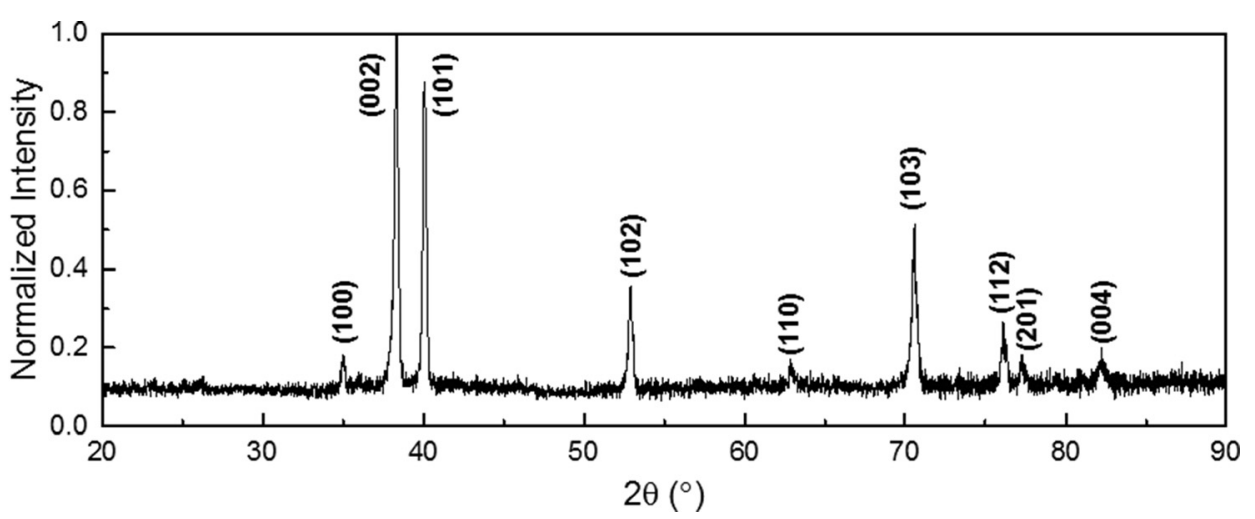

FIG. 2. XRD pattern of the Grade $2 \mathrm{Ti}$ after polishing and prior to FLSP. All detected peaks corresponded to $\alpha$-Ti planes. microscopy (SEM), Focused Ion Beam (FIB), and energy dispersive $\mathrm{X}$-ray spectroscopy (EDS) in an FEI Helios NanoLab 660 DualBeam. X-ray diffraction (XRD) using Cu $\mathrm{K} \alpha$ radiation in a Bruker-AXS D8 Discover $\mathrm{X}$-ray diffractometer provided phase analysis. The Ti sheet was placed on a zero-diffraction $\mathrm{SiO}_{2}$ crystal. Optical microscopy was performed using the Leica DM2700 after etching with solution of hydrofluoric and nitric acids. Ti surfaces were polished through standard metallurgical procedures with final polish using $0.3 \mu \mathrm{m} \mathrm{Al}_{2} \mathrm{O}_{3}$ powder. Before FLSP, the polished substrates were cleaned in an ultrasonic bath through successive submerging in acetone, methanol, and deionized water for $20 \mathrm{~min}$ each.

The FLSP experiments were completed using a Ti:Sapphire femtosecond laser system (Coherent Astrella) producing 6 $\mathrm{mJ}, 35 \mathrm{fs}$ laser pulses at a $1 \mathrm{kHz}$ repetition rate. A computercontrolled shutter system, capable of selecting single laser pulses, was used to control the number of laser pulses incident on the sample. The laser pulse length and chirp were monitored by a Positive Light Model 8-02 Frequency Resolved Optical Grating (FROG) instrument while a half waveplate and polarizer were used to control the laser pulse energy. A Melles Griot Nanomotion II computer-controlled translation stage system, with 3 axes of motion, was used for sample positioning and translation relative to the laser focal volume. A Thorlabs MPD169-P01 parabolic mirror, with $152.4 \mathrm{~mm}$ focal length, was used to focus the femtosecond pulses, which have a Gaussian spatial profile.

The laser spot size, which was used to calculate the laser fluence and pulse count, was determined using the method outlined by Liu. ${ }^{60}$ The ablation spots were created using 100 fs pulses with energy ranging from 50 to $750 \mu \mathrm{J}$ with $50 \mu \mathrm{J}$ increments. The Keyence VK-X 3D Laser Scanning Confocal Microscope (3DLSCM) was used to measure the ablation crater area and calculate the equivalent diameter based on that area.

SEM-FIB cross-sectional milling of the FLSP structures was performed with the FEI Helios NanoLab 660 DualBeam. For the cross-sectioning process, the target mound was protected with platinum $(\mathrm{Pt})$ layers deposited first via electronbeam induced deposition ( $200 \mathrm{~nm}$ thick), and then by ion beam-induced deposition ( $2 \mu \mathrm{m}$ thick). Then, $\mathrm{Ga}^{+}$FIB milling was used to remove approximately half of the mound. Imaging of the cross section was achieved using ion-induced secondary electron (ISE) with the Everhart-Thornley Detector (ETD) at a tilt of $45^{\circ}$.
Transmission electron microscopy (TEM) analysis was performed on three of the five different mound types. TEM samples comprised of thin, electron transparent slices of the structures $(<200 \mathrm{~nm})$ were created using the "liftout procedure" with the FEI Helios NanoLab 660 DualBeam. ${ }^{61}$ The process began with protective Pt layer deposition identical to that for cross-sectioning. FIB milling reduced the target mound into a thin $(\sim 1 \mu \mathrm{m}$ thick $)$ cross section. This slice was attached onto a tungsten needle with Pt welding, then transferred onto a $\mathrm{Cu}$ Omniprobe Lift-Out Grid. The sample was then thinned by FIB milling to $150 \mathrm{~nm}$ for electron transparency. Bright field TEM imaging and selected area electron diffraction (SAED) was performed using an FEI Tecnai Osiris (S)TEM.

\section{RESULTS}

XRD pattern of the Ti substrate is shown in Fig. 2. The XRD peaks indexed to the hexagonal close-packed (HCP) $\alpha-$ phase and peak intensities indicated that the Ti was polycrystalline with no preferred orientation. ${ }^{62}$ The microstructure consisted of $\alpha$-Ti grains with an average size of $14.0 \pm 6.5 \mu \mathrm{m}$ (Fig. 3).

Five unique mound-like surface structures were formed by FLSP on Ti; in the order of increasing laser fluence using the fluence and pulse count values listed in Table I. Each structure type has a unique morphology resulting from different mix of formation processes for the different fluence levels and pulse counts used. These structures are identified in terms of the relative fluence level: they are labeled as M1, M2, M3, M4, and M5 (Table I) and graphically represented

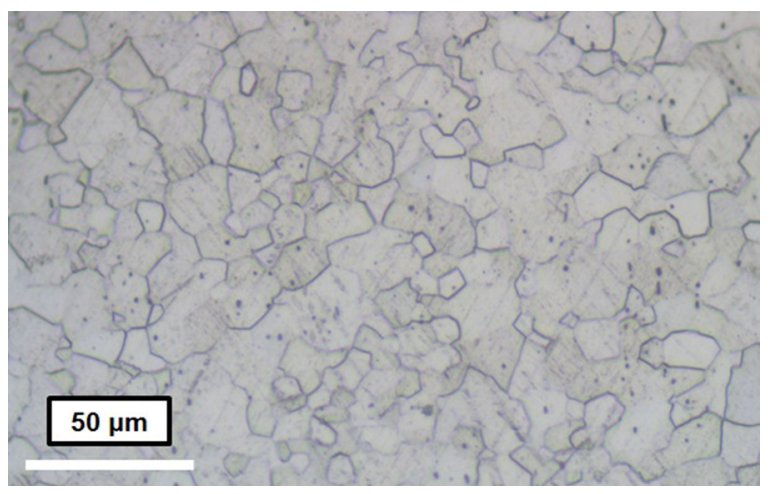

FIG. 3. Optical microscopy image of the microstructure of the unprocessed Ti substrate. 
TABLE I. FLSP parameters for 5 types of surface structures.

\begin{tabular}{lcc}
\hline \hline Surface structure & Laser pulses $(\#)$ & Laser fluence $\left(\mathrm{J} \mathrm{cm}^{-2}\right)$ \\
\hline M1 & 1500 & 0.38 \\
M2 & 1500 & 0.66 \\
M3 & 100 & 0.95 \\
M4 & 1500 & 1.89 \\
M5 & 100 & 3.52 \\
\hline \hline
\end{tabular}
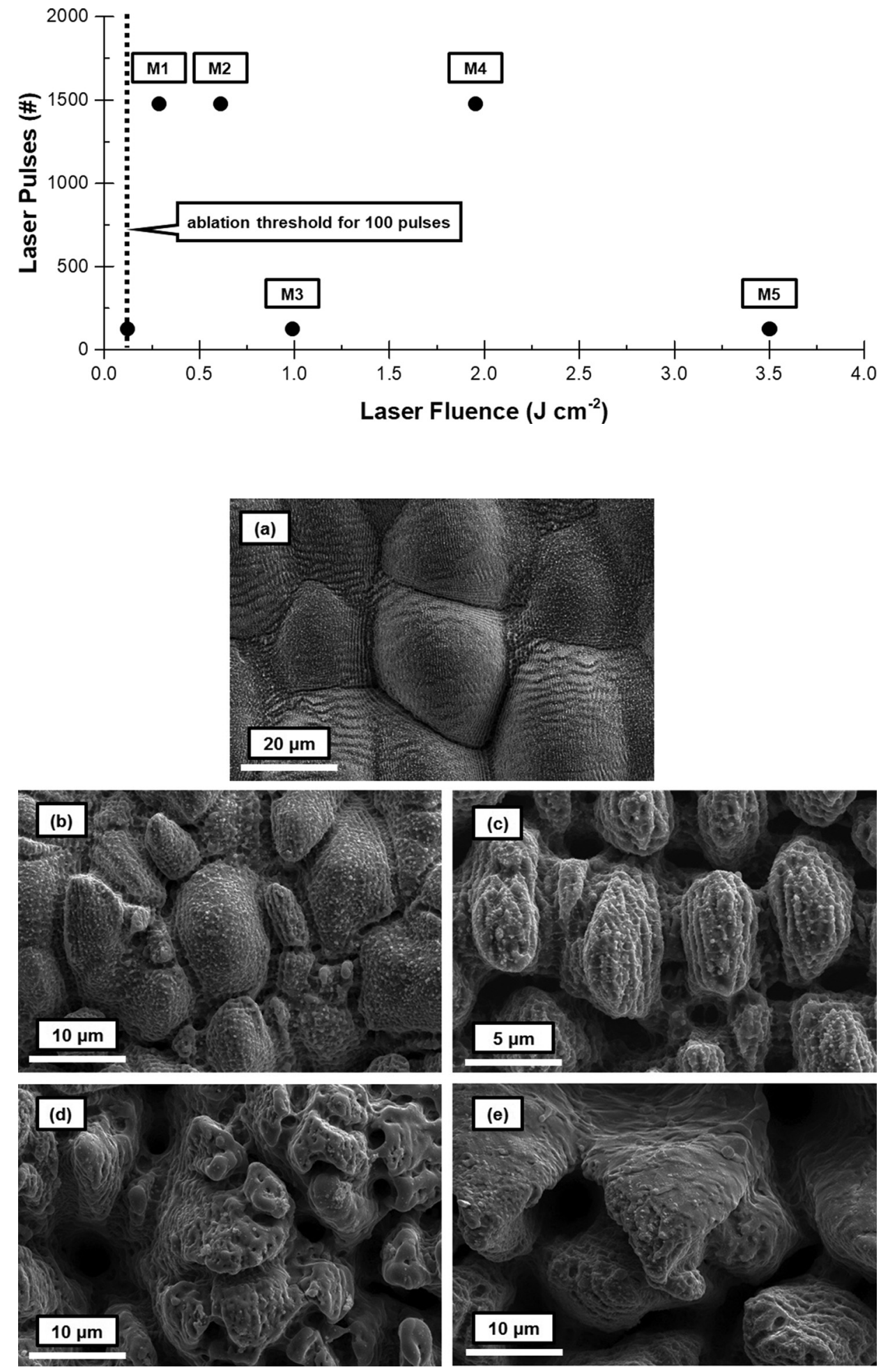

FIG. 4. Ablation threshold of Ti Grade 2 for 100 pulses (determined using method by $\mathrm{Liu}^{60}$ ) and the laser fluence and cumulative pulse count parameters used for generating M1 to M5 surface structures.
FIG. 5. SEM images of (a) M1, (b) M2, (c) M3, (d) M4, and (e) M5 mounds. 

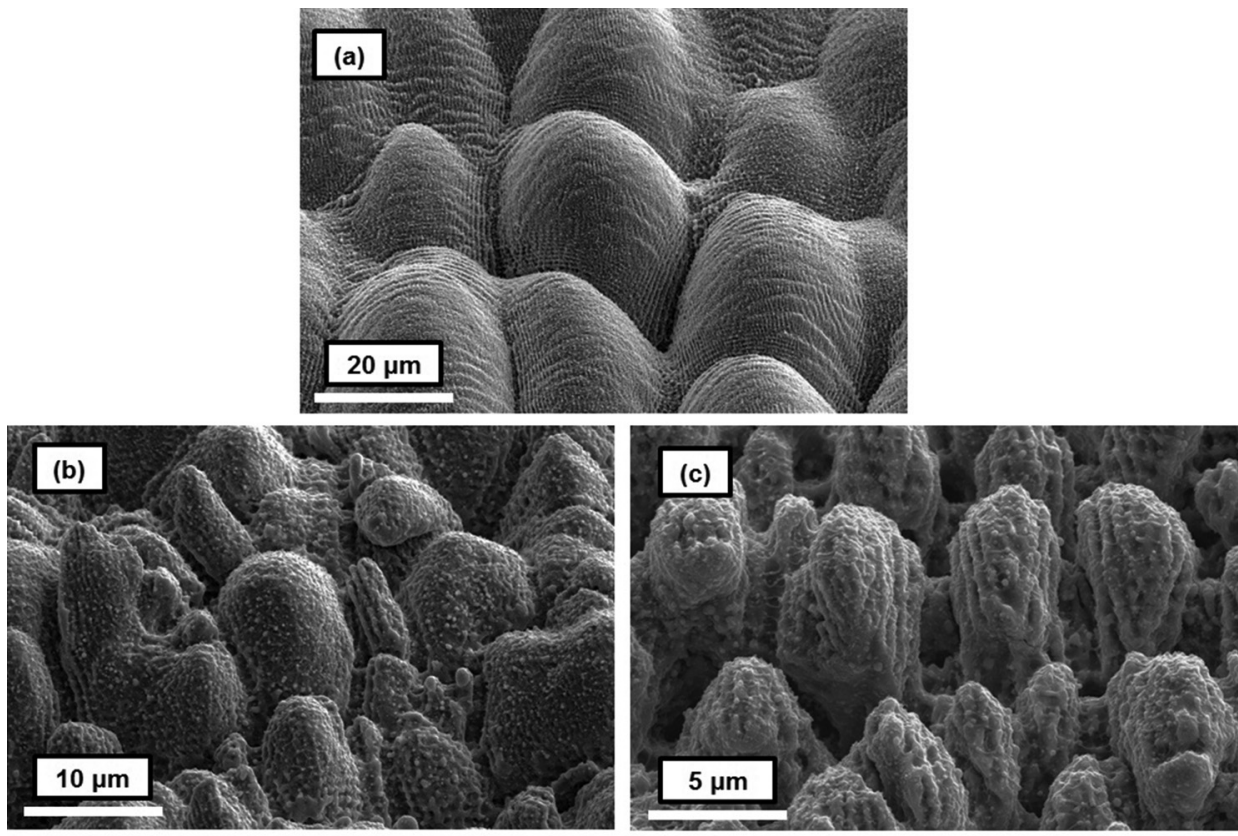

FIG. 6. SEM images at $45^{\circ}$ tilt of (a) M1, (b) M2, (c) M3, (d) M4, and (e) M5 mounds.
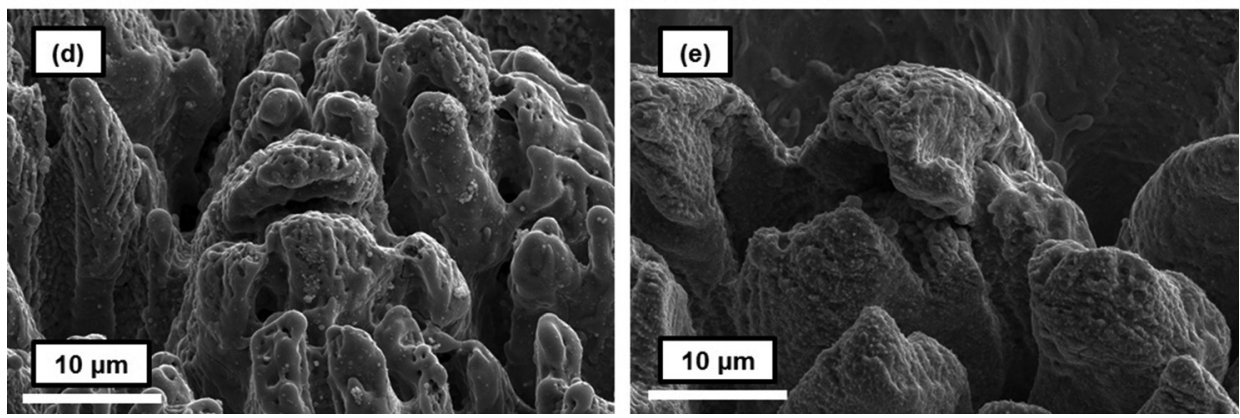

spaced, with each dome covered by periodic ridges reminiscent of LIPSS.

M2 mounds are spaced farther apart from each other and are smaller than M1 mounds, with diameters of 5-10 $\mu \mathrm{m}$.
Figures 5(b) and 6(b) include SEM images of the M2 structures, which were produced using laser fluence about twice that of M1. M3 mounds were produced at a higher fluence value and lower pulse counts are included in Figs. 5(c) and 6(c).
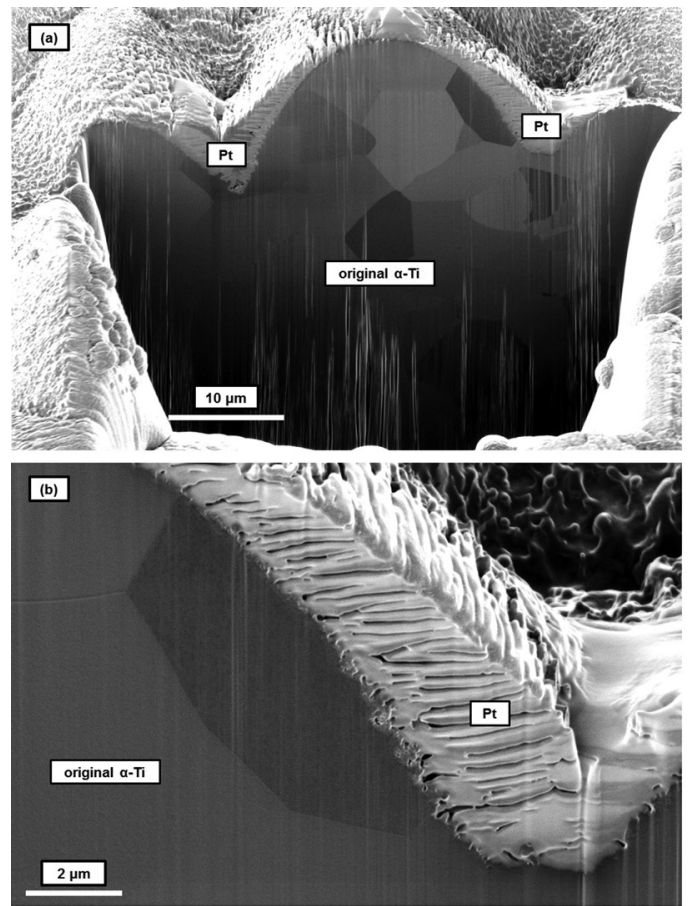

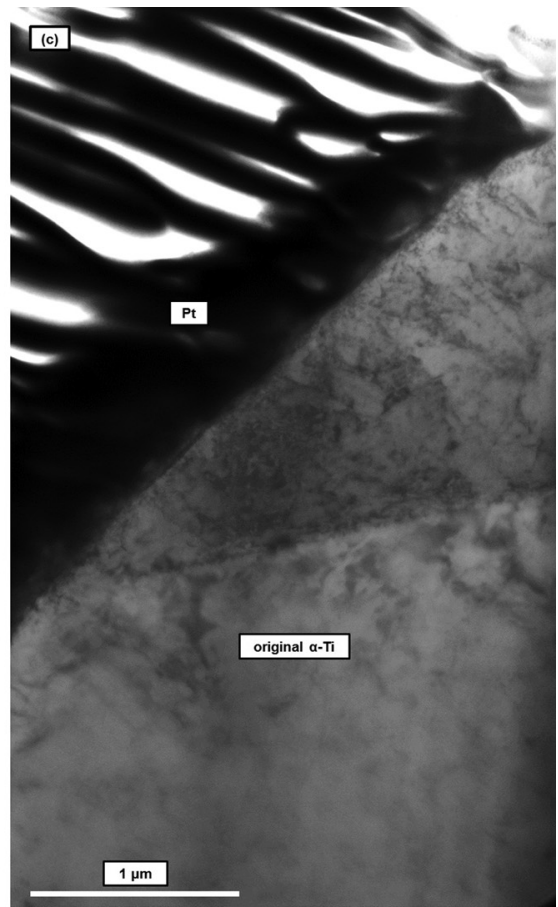

FIG. 7. (a) and (b) SEM images of the M1 mound cross-section showing the grain structure as well as the Pt protective layer. (c) TEM bright field image of the M1 mound's cross-section. 


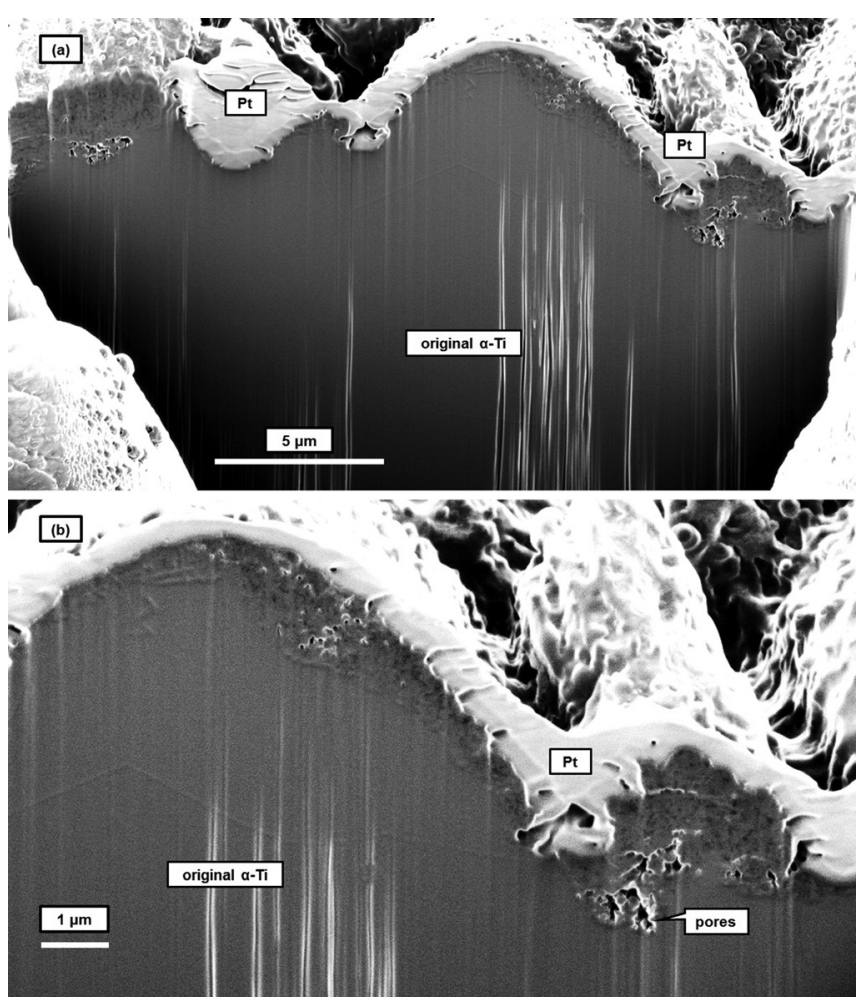

FIG. 8. (a) and (b) SEM images of a M2 mound's cross-section showing the grain structure as well as the Pt protective layer.

M4 and M5 mounds are significantly taller than M1, M2, and M3 mounds. M5 structures, Figs. 5(e) and 6(e), have peaks that protrude above the original surface. M4 and M5 mounds are spaced farther apart from each other, separated by deep pits.

The microstructure underlying the M1 mounds original $\alpha$-Ti grains; they had the same size and morphology as the microstructure of the unprocessed substrate (Fig. 3).

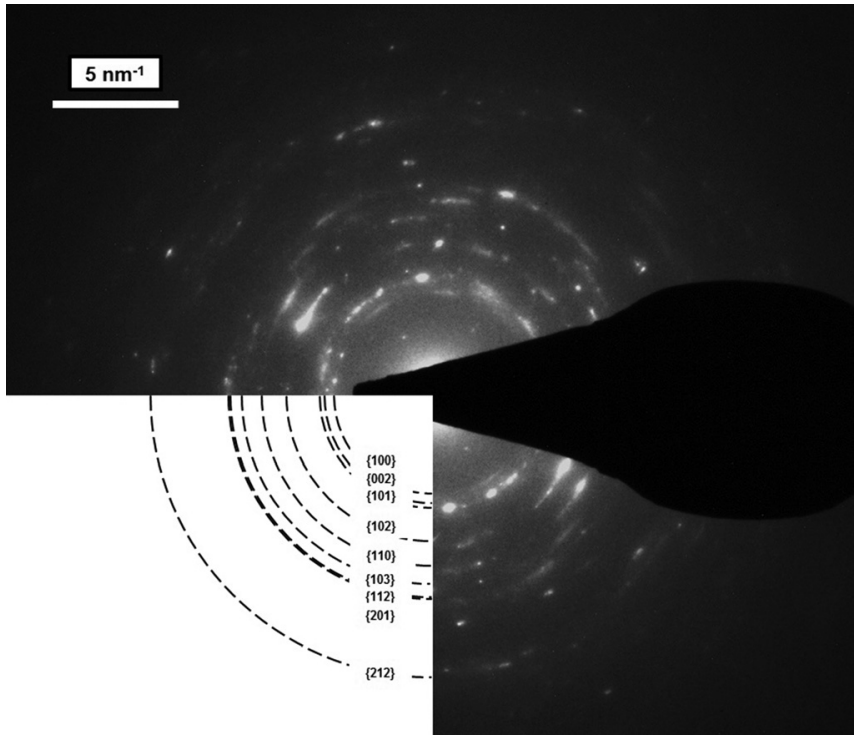

FIG. 10. SAED pattern of resolidified Ti grains from the M3 TEM sample. The dashed lines are the expected positions for each $\alpha$-Ti plane.

TEM bright field imaging revealed that there is no resolidified or otherwise deposited layer at the top of the M1 structure [Fig. 7(c)].

A M2 mound's underlying microstructure reveal that above the original $\alpha$-Ti grains there exists a new layer of smaller grains with porosity (Fig. 8). This is most likely $\mathrm{Ti}$ grains that resolidified after the fluid flow formation process.

The M3 mounds consist of two distinct layers: large, original $\alpha$-Ti grains at the base of the mounds and a region with significantly smaller, resolidified Ti grains (Fig. 9). This finer-grained region is also porous, as seen in Fig. 9(b).

The black circle on Fig. 9(c) shows the region from where the SAED pattern of Fig. 10 was taken. The presence of rings in the SAED pattern indexed to the $\alpha$-Ti phase and
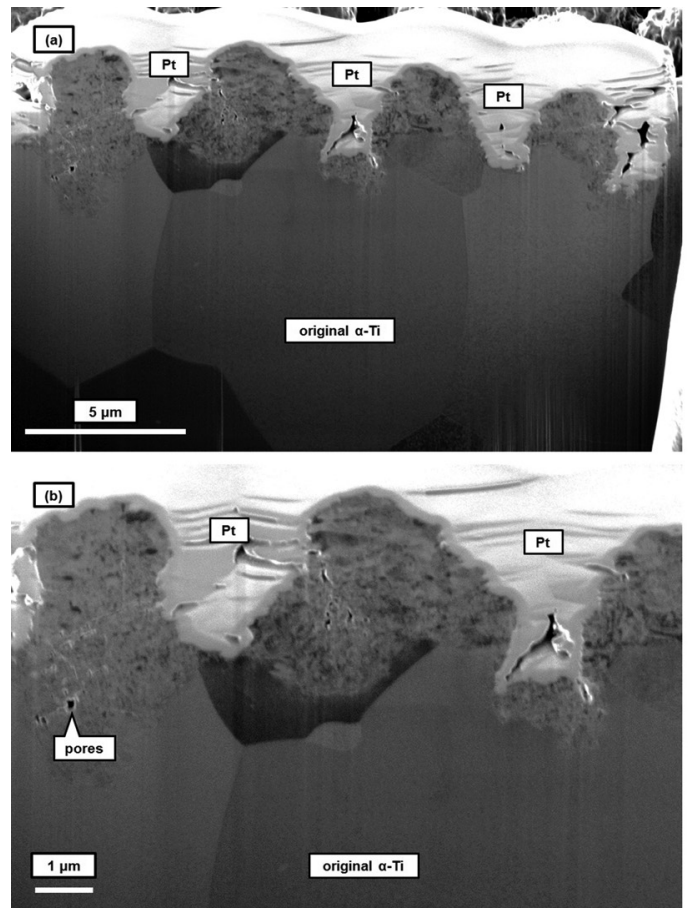

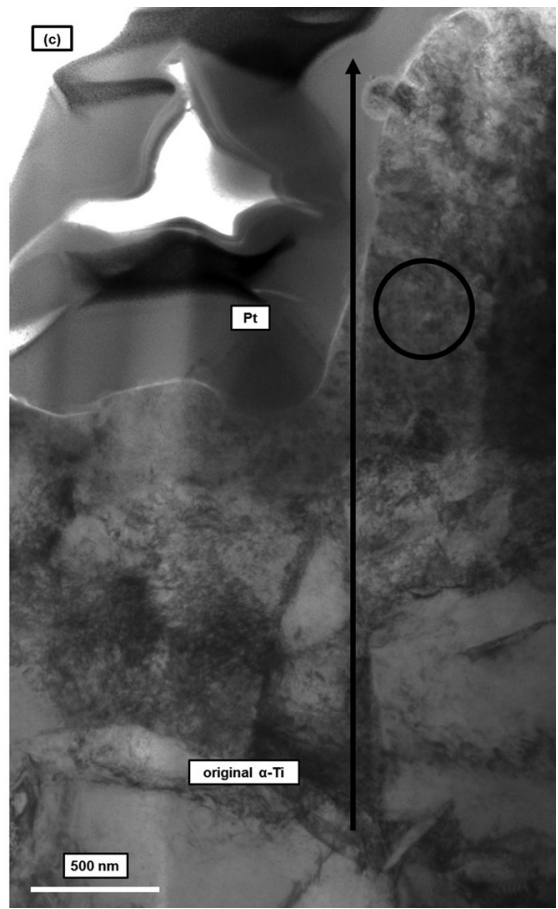

FIG. 9. (a) and (b) SEM images of M3 mounds' cross-section showing the grain structure as well as the Pt protective layer. (b) TEM bright field image of M3 mound's cross-section. 


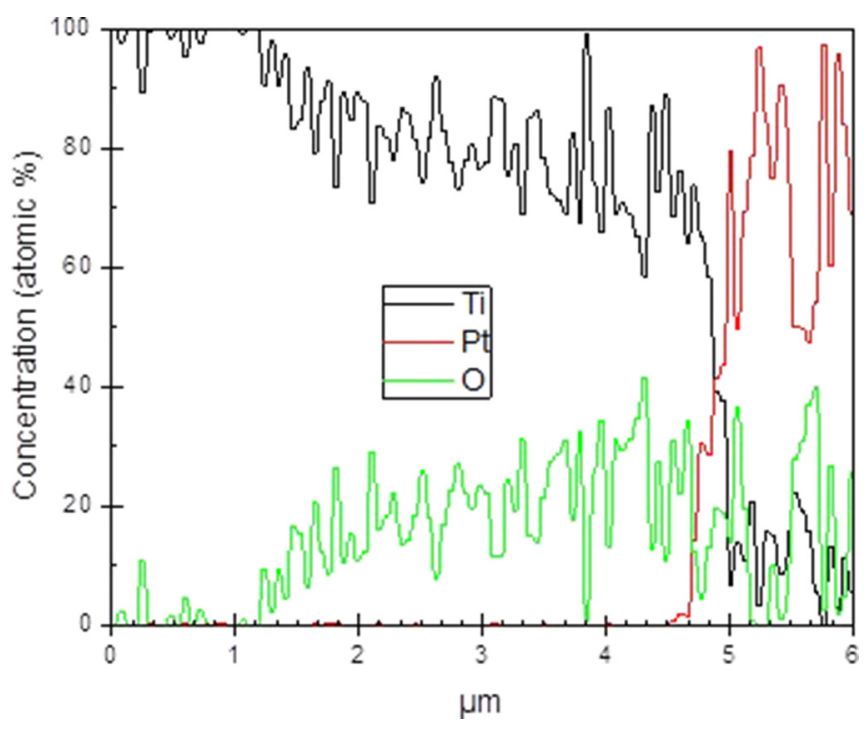

FIG. 11. EDX line scan across a section of the M3 TEM sample.

indicates that the resolidified region is polycrystalline. However, there are some unaccounted-for reflections that may indicate the presence of $\beta$-Ti.

The chemical composition profile of the cross-sectioned M3 mound was determined by an energy-dispersive X-ray spectroscopy (EDX) line scan across the resolidified zone. The path, as indicated by the black arrow on Fig. 9(c), starts in the original $\alpha$-Ti region (corresponding to " 0 " in Fig. 11), passes through the resolidified $\alpha$-Ti, and ends at the Pt protective layer. The profile provided corroborating evidence of the three layers: nearly completely $\mathrm{Ti}$ in the larger-grain $\alpha$-Ti area, approximately 25 at. $\% \mathrm{O}$ and 75 at. $\% \mathrm{Ti}$ for the finergrained $\alpha$-Ti region, and a high concentration of $\mathrm{Pt}$ at the protective layer. The TEM sample was approximately $200 \mathrm{~nm}$ thick, so there was likely an overlap between the Pt protective layer and the resolidified layer, causing the presence of Ti and $\mathrm{O}$ at the end of the EDX line scan.

The underlying microstructure of a M4 mound is similar to that of the M3 mound, with a finer-grained layer on top of the original, larger $\alpha$-Ti grains (Fig. 12). However, this resolidified layer was significantly thicker due to the higher fluence.

Figure 13 shows the cross section of an M5 mound. The SEM images revealed a primary M5 mound in the center as well as a section of another M5 mound that lay just behind and over the first mound. The top peak protrudes up to $10 \mu \mathrm{m}$ higher than the original $\mathrm{Ti}$ substrate surface, as indicated by the dotted black line. Just like the M3 mound, the M5 mound contains a resolidification region consisting of finer grains that is above the larger original $\alpha$-Ti grains which can be seen in Fig. 13(a). The pores in the M5 mound cross-section are larger than those present in the M3 mounds.

The black circle on Fig. 13(c) indicates the region from which the SAED pattern of Fig. 14 was taken. Like that of the M3 TEM sample, the resolidified region of the M5 mound is polycrystalline and comprises mostly of $\alpha$-Ti. However, there are some reflections that may indicate the presence of $\beta$-Ti.
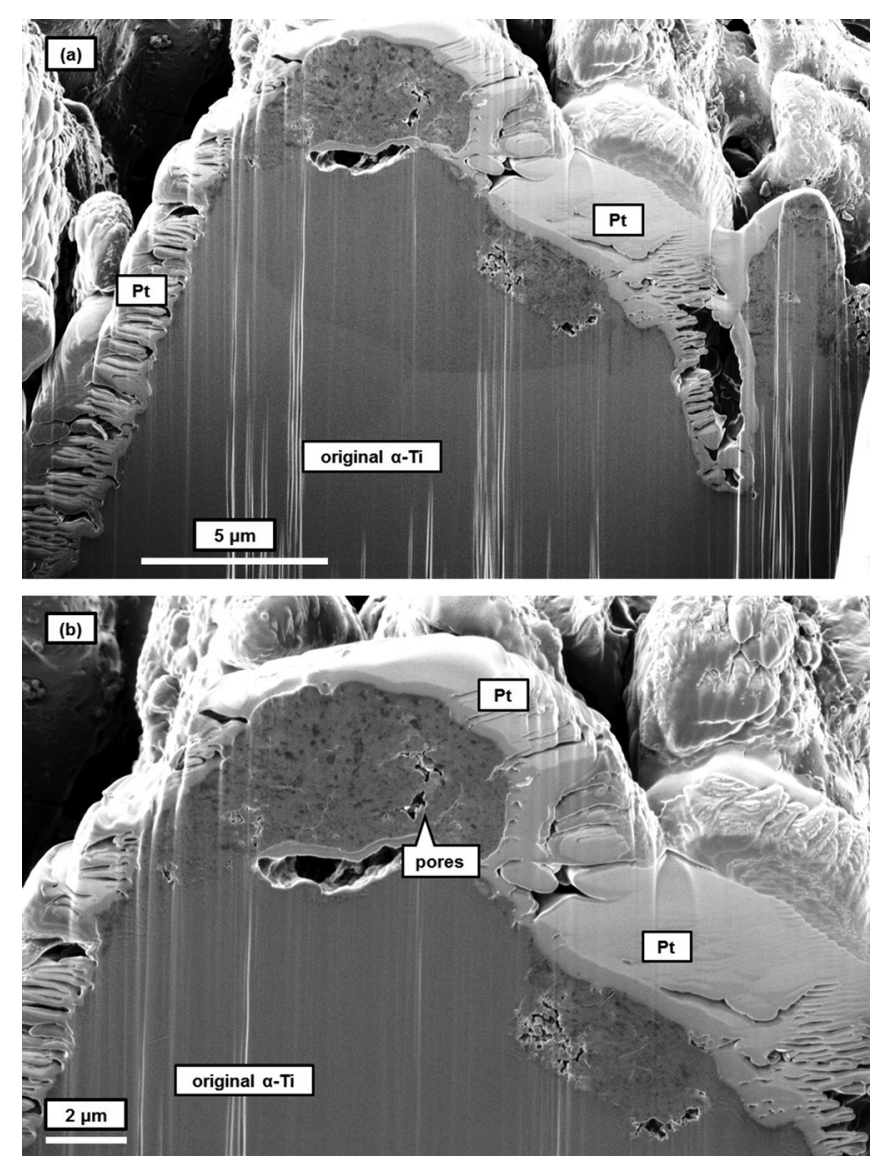

FIG. 12. (a) and (b) SEM images of a M4 mound's cross-section showing the grain structure as well as the Pt protective layer.

\section{DISCUSSION}

The internal microstructures of surface mounds formed by FLSP using different fluence and pulse count values provide physical evidence of their formation process.

First, M1 mounds appear to form primarily through ablation, with minimal fluid flow. Material removal due to ablation appeared to be the dominant process the substrate experienced during FLSP processing. SEM and TEM images (Fig. 7) revealed retention of the original $\alpha$-Ti microstructure within the M1 mound. The ripples that overlay the M1 mounds indicate melting at the Ti surface $\left(\mathrm{T}>\mathrm{T}_{\mathrm{m}}=1700 \mathrm{~K}\right)$, similar to what was previously observed for FLSP of Ni (Ref. 63) and simulated for FLSP of Ti. ${ }^{64}$ However, thermal excursions were minimal, evidenced by the lack of regions showing different grains and/or phases. Melting was only observed at the top of the M1 mounds $(<1 \mu \mathrm{m})$, while the subsurface $\mathrm{Ti}$ (the majority of the mound) experienced temperatures below that which would induce melting and subsequent fluid flow and resolidification. M1 mounds were processed at significantly lower laser fluence than BSG and ASG mounds. Therefore, fluid flow was minimal and not expected to play a significant role in the formation of the M1 mounds. This was confirmed by the microstructural analysis.

In this paper, ablation is used to refer to material removal by ultrafast laser pulse interaction with the surface. As described by Ahmmed et al., the mechanisms for ablation during FLSP are dependent on the material properties, laser 

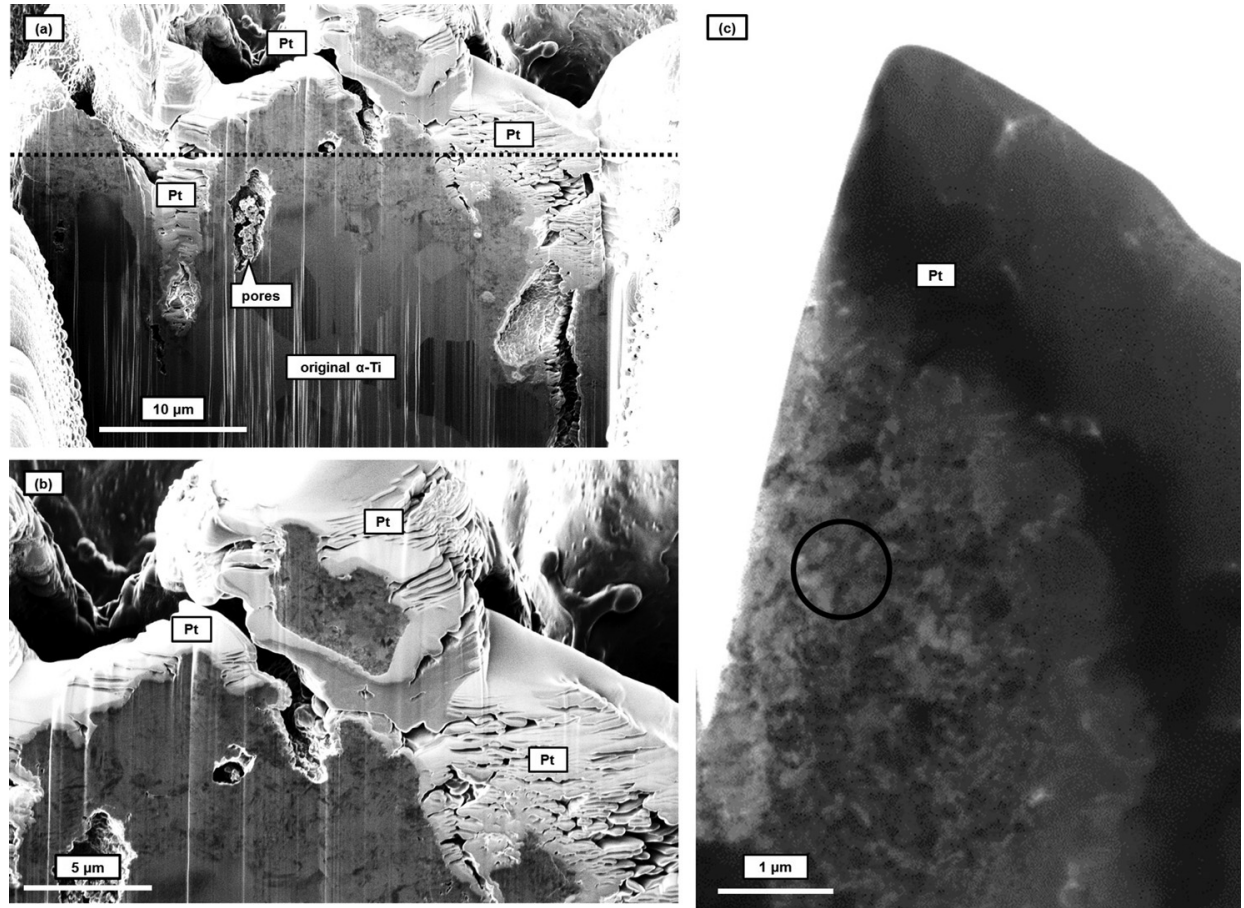

FIG. 13. (a) and (b) SEM images of the M5 mound cross-section showing the grain structure as well as the $\mathrm{Pt}$ protective layer. (c) TEM bright field image of M5 mound's cross-section.

properties, and processing environment. ${ }^{65}$ There have been many different mechanisms proposed to explain ablation of metals by ultrafast laser processing. It is beyond the scope of this study to measure the temperature reached during FLSP of Ti, and to determine the exact mechanisms of ablation.

These M1 mounds on Ti are therefore analogous to several other types of FLSP structures formed on other surfaces. Previous work on the easy glass-forming alloy $\mathrm{Ni}_{60} \mathrm{Nb}_{40}$ demonstrated that lower fluence mound-like surface structures also formed by ablation, not fluid flow. ${ }^{54,58}$ Zuhlke et al. utilized pulse-by-pulse SEM imaging of mound growth to conclude that PVA was responsible for low fluence BSG mounds grown on Ni 200/201. ${ }^{5}$ Sher et al. ${ }^{66}$ credited PVA

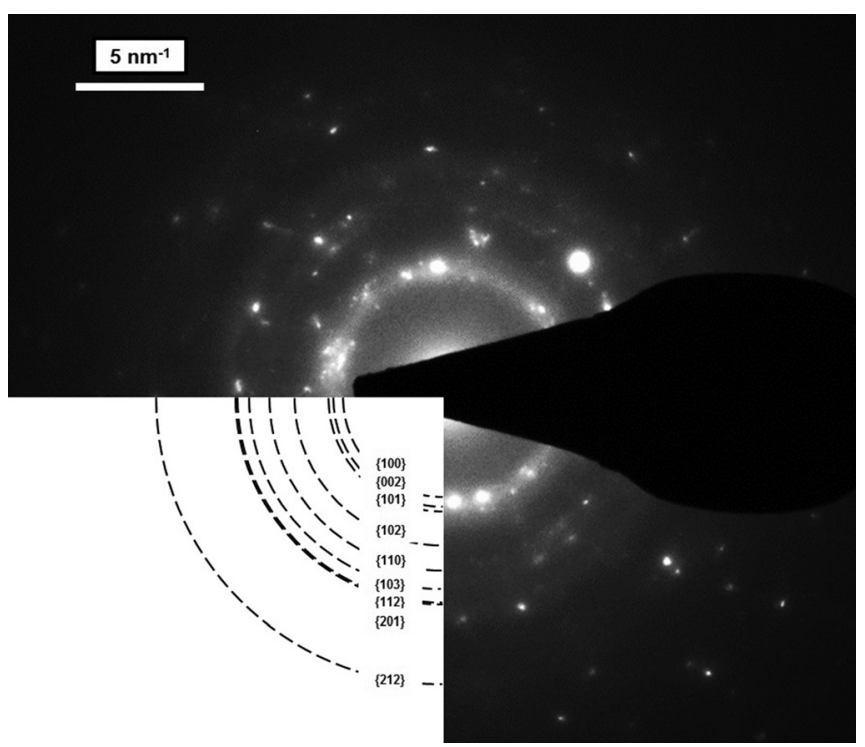

FIG. 14. SAED pattern of resolidified Ti grains from the M5 TEM sample. The dashed lines are the expected positions for each $\alpha$-Ti plane. for creating spike-like surfaces on Si wafers. Zhu et al. ${ }^{67}$ examined the differences between picosecond and femtosecond $\mathrm{Si}$ processing, and concluded that ablation and not fluid flow occurs during FLSP due to the timescales of energy relaxation processes.

The M2 and M4 mounds were processed at the same number (1500) of laser pulses but at a higher fluence. Their underlying microstructures (Figs. 8 and 12) demonstrated that at higher laser energy, resolidification becomes more prevalent compared to M1 mounds that were processed using a lower fluence. The resolidified layer accounted for a small fraction $(<20 \%)$ of the total M2 and M4 mound heights. For the bulk of the microstructure, at depths into the surface beyond the surface melt, the original $\alpha$-Ti grains remained. The larger percentage of unaltered material compared to the resolidified, fthe iner grained layer indicated that preferential ablation still played a significant role in the formation of M2 and M4 mounds. This transition from ablation-dominated formation at A low fluence to melting/resolidification-dominated formation at high fluence is analogous to that of BSG to ASG mounds as reported by previous research on $\mathrm{Ni}$ (Refs. 5 and 43) and $\mathrm{Ni}_{60} \mathrm{Nb}_{40} \cdot{ }^{54,58}$

For M3 and M5 mounds, the resolidified Ti layer was most likely caused by Marangoni effect-driven fluid flow. The molten Ti that was driven toward the top of the peaks resolidifies rapidly due to the large heat sink provided by the base metal, forming smaller Ti grains. M5 mounds have a thicker resolidification layer than M3 mounds, which appears to be due to the higher fluence which generates more molten Ti.

The porosity present in this resolidification layer also confirms liquification/fluid flow, as solidification of titanium produces more porosity than other metals. ${ }^{68}$ Such porosity can be from gas bubbles ${ }^{69}$ or shrinkage. ${ }^{70}$ The FLSP was performed in air and the laser-induced melt experienced rapid resolidification; both can cause the voids observed in the cross-section microstructure of M3 and M5 mounds. 
Pores are larger inside M5 than M3 mounds, likely as the result of the thicker resolidified layer.

Porosity within these higher fluence mounds has consequences for proposed applications of FLSP on Ti. Biomedical uses such as implants may be comprised by the decrease in mechanical strength due to the pores. ${ }^{28,29}$ The advantages of preventing bacterial growth and improving bonding with bone tissues maybe outweighed by disadvantages of weaker titanium surfaces. The same concerns apply for tribological ${ }^{37,38}$ and molding applications. ${ }^{39}$

The formation of M2 to M5 Ti surface structures are analogous to other ultrafast laser-processed surface structures that form with the fluid flow. These include ASG mounds on $\mathrm{Ni}_{60} \mathrm{Nb}_{40}$ (Refs. 54 and 58) and Ni 200/201 (Ref. 5) as well as "columns" and "spikes" on Si wafers. ${ }^{55,71}$

The ultrafast laser processing was performed in air, so titanium oxide formation was possible. However, no clear evidence of $\mathrm{TiO}_{2}$ formation in the resolidification layer was seen in SAED patterns of M3 (Fig. 10) nor M5 mounds (Fig. 14). It is possible that oxygen from atmosphere was incorporated into the resolidified layer during the laser processing. Oxygen has a very high solubility in $\alpha$-Ti, especially at elevated temperatures commonly experienced during FLSP $\left(31.9\right.$ at. $\%$ at $\left.600{ }^{\circ} \mathrm{C}\right) .^{72,73}$ Much of the existing literature on ultrafast processing of titanium did not include information on the underlying microstructure of the surface structures. However, Bereznai et al. concluded that laser processing of commercially pure titanium did not alter the original $\alpha-\mathrm{Ti}^{74}$

\section{CONCLUSION}

The formation processes of mound-like surface structures formed by ultrafast laser processing of Ti using different fluence and pulse count values were determined by examining the underlying microstructure. A dual-beam focused ion beam-scanning electron microscope was utilized to create cross sections for secondary electron imaging, bright field transmission electron microscopy imaging, and selected area electron diffraction. The lowest fluence class of Ti surface structures was found to form primarily by ablation. By examining a cross-section of these low fluence mounds, the original $\alpha$-Ti microstructure was observed without evidence of resolidification or redeposition. The microstructure of higher fluence surface structures was found to contain a resolidified layer of finer-grained $\alpha$-Ti. This was evidence of formation by hydrodynamical fluid flow, where the laser processing melts and drives such a molten layer from the valleys to the peaks of the mounds. These experimental evidences corroborate proposed formation processes for laser processed surface structures and can improve $\mathrm{Ti}$ functionalization for future biomedical and optical applications.

\section{ACKNOWLEDGMENTS}

This work was supported by the National Aeronautics and Space Administration (NASA) Experimental Program to Stimulate Competitive Research (EPSCoR) Grant No. \#NNX13AB17A and the Office of Naval Research (ONR) Contract Nos. \#FA4600-12-D-9000-0045 and \#FA4600-12-
D-9000-0057. Research was performed in the facilities of the Nebraska Center for Materials and Nanoscience $(\mathrm{NCMN})$ and the NanoEngineering Research Core Facility (NERCF), which are supported by the Nebraska Research Initiative (NRI).

${ }^{1}$ K. Sugioka and Y. Cheng, Light: Sci. Appl. 3, 1-12 (2014).

${ }^{2}$ A. Y. Vorobyev and C. Guo, Laser Photonics Rev. 7(3), 385-407 (2013).

${ }^{3} \mathrm{~K}$. Sugioka and Y. Cheng, Femtosecond Laser 3D Micromachining for Microfluidic and Optofluidic Applications (Springer, London, 2014), pp. 19-33.

${ }^{4}$ A. Y. Vorobyev and C. Guo, Sci. Adv. Mater. 4(3-4), 432-438 (2012).

${ }^{5}$ C. A. Zuhlke, T. P. Anderson, and D. R. Alexander, Opt. Express 21(7), 8460-8473 (2013).

${ }^{6}$ M. Tsukamoto, T. Kayahara, H. Nakano, M. Hashida, M. Katto, M. Fujita, M. Tanaka, and N. Abe, J. Phys.: Conf. Ser. 59(1), 666-669 (2007).

${ }^{7}$ E. J. Y. Ling, J. Saïd, N. Brodusch, R. Gauvin, P. Servio, and A.-M. Kietzig, Appl. Surf. Sci. 353, 512-521 (2015).

${ }^{8}$ B. K. Nayak and M. C. Gupta, Opt. Lasers Eng. 48(10), 940-949 (2010).

${ }^{9}$ A. Pan, A. Dias, M. Gomez-Aranzadi, S. M. Olaizola, and A. Rodriguez, J. Appl. Phys. 115(17), 173101 (2014).

${ }^{10}$ K. N. Barada, C. G. Mool, and W. K. Kurt, Nanotechnology 18(19), 195302 (2007).

${ }^{11}$ B. R. Tull, J. E. Carey, E. Mazur, J. P. McDonald, and S. M. Yalisove, MRS Bull. 31(08), 626-633 (2006).

${ }^{12}$ E. Rebollar, M. Castillejo, and T. A. Ezquerra, Eur. Polym. J. 73, 162-174 (2015).

${ }^{13}$ E. Rebollar, J. R. Vazquez de Aldana, I. Martin-Fabiani, M. Hernandez, D. R. Rueda, T. A. Ezquerra, C. Domingo, P. Moreno, and M. Castillejo, Phys. Chem. Chem. Phys. 15(27), 11287-11298 (2013).

${ }^{14}$ H. Pazokian, A. Selimis, B. Jalal, J. Saeid, M. Mahmoud, C. Fotakis, and E. Stratakis, J. Micromech. Microeng. 22(3), 035001 (2012).

${ }^{15}$ L. B. Boinovich, A. G. Domantovskiy, A. M. Emelyanenko, A. S. Pashinin, A. A. Ionin, S. I. Kudryashov, and P. N. Saltuganov, ACS Appl. Mater. Interfaces 6(3), 2080-2085 (2014).

${ }^{16}$ M. S. Ahsan, F. Dewanda, M. S. Lee, H. Sekita, and T. Sumiyoshi, Appl. Surf. Sci. 265, 784-789 (2013).

${ }^{17}$ D. Sciti, L. Silvestroni, D. M. Trucchi, E. Cappelli, S. Orlando, and E. Sani, Sol. Energy Mater. Sol. Cells 132, 460-466 (2015).

${ }^{18}$ Y. Xing, J. Deng, Y. Lian, K. Zhang, G. Zhang, and J. Zhao, Appl. Surf. Sci. 289, 62-71 (2014).

${ }^{19}$ H. Wang, P. Kongsuwan, G. Satoh, and Y. L. Yao, J. Manuf. Sci. Eng. 134(3), 10 (2012).

${ }^{20}$ V. V. Iyengar, B. K. Nayak, and M. C. Gupta, Sol. Energy Mater. Sol. Cells 94(12), 2251-2257 (2010).

${ }^{21}$ M. Lancry, R. Desmarchelier, K. Cook, J. Canning, and B. Poumellec, presented at the Advanced Photonics, Barcelona (2014).

${ }^{22}$ S. Zhou, X. Pi, Z. Ni, Q. Luan, Y. Jiang, C. Jin, T. Nozaki, and D. Yang, Part. Part. Syst. Charact. 32(2), 213-221 (2015).

${ }^{23}$ C. M. Kruse, T. Anderson, C. Wilson, C. Zuhlke, D. Alexander, G. Gogos, and S. Ndao, Int. J. Heat Mass Transfer 82, 109-116 (2015).

${ }^{24}$ A. Y. Vorobyev and C. Guo, in Advanced Lasers, edited by O. Shulika and I. Sukhoivanov (Springer, Netherlands, 2015), Vol. 193, pp. 101-115.

${ }^{25}$ C. Kruse, T. Anderson, C. Wilson, C. Zuhlke, D. Alexander, G. Gogos, and S. Ndao, Langmuir 29(31), 9798-9806 (2013).

${ }^{26}$ V. Zorba, E. Stratakis, M. Barberoglou, E. Spanakis, P. Tzanetakis, S. H. Anastasiadis, and C. Fotakis, Adv. Mater. 20(21), 4049-4054 (2008).

${ }^{27}$ G. Li, Y. Lu, P. Wu, Z. Zhang, J. Li, W. Zhu, Y. Hu, D. Wu, and J. Chu, J. Mater. Chem. A 3, 18675-18683 (2015).

${ }^{28}$ S. G. Steinemann, Periodontology 2000 17(1), 7-21 (1998).

${ }^{29}$ M. Özcan and C. Hämmerle, Materials 5(12), 1528-1545 (2012).

${ }^{30}$ J. R. Bush, B. K. Nayak, L. S. Nair, M. C. Gupta, and C. T. Laurencin, J. Biomed. Mater. Res., Part B: Appl. Biomater. 97B(2), 299-305 (2011).

${ }^{31}$ P. Aliuos, E. Fadeeva, M. Badar, A. Winkel, P. P. Mueller, A. Warnecke, B. Chichkov, T. Lenarz, U. Reich, and G. Reuter, J. Biomed. Mater. Res., Part A 101A(4), 981-990 (2013).

${ }^{32}$ H. Li, Y. Lai, J. Huang, Y. Tang, L. Yang, Z. Chen, K. Zhang, X. Wang, and L. P. Tan, J. Mater. Chem. B 3(3), 342-347 (2015).

${ }^{33}$ V. V. Iyengar, B. K. Nayak, and M. C. Gupta, Appl. Opt. 49(31), 5983-5988 (2010). 
${ }^{34}$ A. Y. Vorobyev, A. N. Topkov, O. V. Gurin, V. A. Svich, and C. Guo, Appl. Phys. Lett. 95(12), 121106 (2009).

${ }^{35} \mathrm{~A}$. Y. Vorobyev and C. Guo, presented at the 2009 52nd IEEE International Midwest Symposium on Circuits and Systems, 2009.

${ }^{36}$ M. H. Dar, R. Kuladeep, and V. Saikiran, Appl. Surf. Sci. 371, 479-487 (2016).

${ }^{37}$ J. Bonse, R. Koter, M. Hartelt, D. Spaltmann, S. Pentzien, S. Höhm, A. Rosenfeld, and J. Krüger, Appl. Phys. A 117(1), 103-110 (2014).

${ }^{38}$ J. Bonse, R. Koter, M. Hartelt, D. Spaltmann, S. Pentzien, S. Höhm, A. Rosenfeld, and J. Krüger, Appl. Surf. Sci. 336, 21-27 (2015).

${ }^{39}$ T. Jiang, J. Koch, C. Unger, E. Fadeeva, A. Koroleva, Q. Zhao, and B. N. Chichkov, Appl. Phys. A 108(4), 863-869 (2012).

${ }^{40}$ C. A. Zuhlke, T. P. Anderson, and D. R. Alexander, Appl. Phys. Lett. 103(12), 121603 (2013).

${ }^{41}$ C. A. Zuhlke, T. P. Anderson, and D. R. Alexander, Appl. Surf. Sci. 283, 648-653 (2013).

${ }^{42}$ C. A. Zuhlke, D. R. Alexander, J. C. Bruce, N. J. Ianno, C. A. Kamler, and W. Yang, Opt. Express 18(5), 4329-4339 (2010).

${ }^{43}$ C. A. Zuhlke, Ph.D. Dissertation, University of Nebraska-Lincoln, 2012.

${ }^{44}$ B. K. Nayak, M. C. Gupta, and K. W. Kolasinski, Appl. Phys. A 90(3), 399-402 (2008).

${ }^{45}$ Y. Li, Z. Cui, W. Wang, C. Lin, and H.-L. Tsai, Appl. Surf. Sci. 324, 775-783 (2015).

${ }^{46}$ G. D. Tsibidis, M. Barberoglou, P. A. Loukakos, E. Stratakis, and C. Fotakis, Phys. Rev. B 86, 115316 (2012).

${ }^{47}$ G. D. Tsibidis, C. Fotakis, and E. Stratakis, Phys. Rev. B 92(4), 041405 (2015).

${ }^{48}$ G. D. Tsibidis, E. Stratakis, and K. E. Aifantis, J. Appl. Phys. 111(5), 053502 (2012).

${ }^{49}$ K. Kuršelis, R. Kiyan, and B. N. Chichkov, Appl. Surf. Sci. 258(22), 8845-8852 (2012).

${ }^{50}$ S. Moradi, S. Kamal, P. Englezos, and S. G. Hatzikiriakos, Nanotechnology 24(41), 415302 (2013).

${ }^{51}$ M. D. Shirk and P. A. Molian, J. Laser Appl. 10(1), 18-28 (1998).

${ }^{52}$ P. A. Atanasov, N. N. Nedialkov, S. E. Imamova, A. Ruf, H. Hügel, F. Dausinger, and P. Berger, Appl. Surf. Sci. 186(1-4), 369-373 (2002).

${ }^{53}$ S. Amoruso, R. Bruzzese, X. Wang, N. N. Nedialkov, and P. A. Atanasov, J. Phys. D: Appl. Phys. 40(2), 331 (2007).
${ }^{54}$ E. Peng, A. Tsubaki, C. A. Zuhlke, M. Wang, R. Bell, M. J. Lucis, T. P. Anderson, D. R. Alexander, G. Gogos, and J. E. Shield, Appl. Phys. Lett. 108(3), 031602 (2016).

${ }^{55}$ F. Sánchez, J. L. Morenza, R. Aguiar, J. C. Delgado, and M. Varela, Appl. Phys. A 66(1), 83-86 (1998).

${ }^{56}$ D. Snow, in Emergent Process Methods for High-Technology Ceramics, edited by R. Davis, H. Palmour III, and R. Porter (Springer US, 1984), Vol. 17, pp. 461-471.

${ }^{57}$ J. Jia, M. Li, and C. V. Thompson, Appl. Phys. Lett. 84(16), 3205-3207 (2004).

${ }^{58}$ E. Peng, A. Tsubaki, C. A. Zuhlke, M. Wang, R. Bell, M. J. Lucis, T. P. Anderson, D. R. Alexander, G. Gogos, and J. E. Shield, Appl. Surf. Sci. 396, 1170-1176 (2016).

${ }^{59}$ G. Lütjering and J. C. Williams, Titanium (Springer, 2003).

${ }^{60}$ J. M. Liu, Opt. Lett. 7(5), 196-198 (1982).

${ }^{61}$ D. B. Williams and C. B. Carter, Transmission Electron Microscopy: A Textbook for Materials Science (Springer, 2009).

${ }^{62}$ B. D. Cullity and S. R. Stock, Elements of X-ray Diffraction (Prentice Hall, 2001)

${ }^{63}$ G. D. Tsibidis, E. Skoulas, and E. Stratakis, Opt. Lett. 40(22), 5172-5175 (2015).

${ }^{64}$ Y. Levy, T. J. Y. Derrien, N. M. Bulgakova, E. L. Gurevich, and T. Mocek, Appl. Surf. Sci. 374, 157-164 (2016).

${ }^{65}$ K. Ahmmed, C. Grambow, and A.-M. Kietzig, Micromachines 5(4), 1219 (2014).

${ }^{66}$ M.-J. Sher, M. T. Winkler, and E. Mazur, MRS Bull. 36(06), 439-445 (2011).

${ }^{67}$ J. Zhu, G. Yin, M. Zhao, D. Chen, and L. Zhao, Appl. Surf. Sci. 245(1-4), 102-108 (2005).

${ }^{68}$ M. Wu, J. Schädlich-Stubenrauch, M. Augthun, P. R. Sahm, and H. Spiekermann, Dent. Mater. 14(5), 321-328 (1998).

${ }^{69}$ K. I. Suzuki, K. Nishikawa, and S. Watakabe, Mater. Trans., JIM 37(12), 1793-1801 (1996).

${ }^{70}$ H. Herø, M. Syverud, and M. Waarli, Dent. Mater. 9(1), 15-18 (1993).

${ }^{71}$ F. Sánchez, J. L. Morenza, and V. Trtik, Appl. Phys. Lett. 75(21), 3303-3305 (1999).

${ }^{72} \mathrm{P}$. Waldner and G. Eriksson, Calphad 23(2), 189-218 (1999).

${ }^{73}$ P. Waldner, Scr. Mater. 40(8), 969-974 (1999).

${ }^{74}$ M. Bereznai, I. Pelsöczi, Z. Tóth, K. Turzó, M. Radnai, Z. Bor, and A. Fazekas, Biomaterials 24(23), 4197-4203 (2003). 